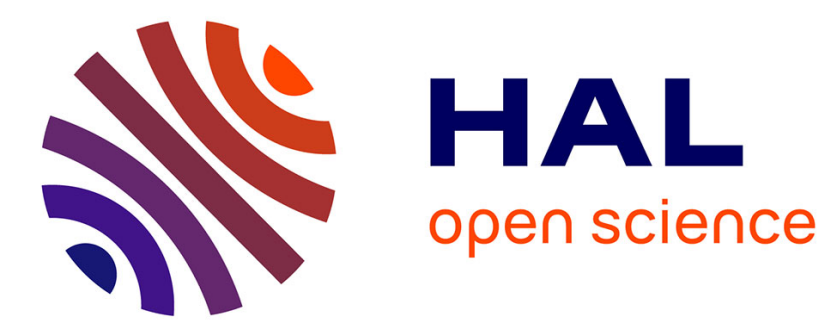

\title{
Trace metal determination in total atmospheric deposition in rural and urban areas
}

Sam Azimi, Alexandre Ludwig, Daniel R. Thevenot, Jean-Louis Colin

\section{To cite this version:}

Sam Azimi, Alexandre Ludwig, Daniel R. Thevenot, Jean-Louis Colin. Trace metal determination in total atmospheric deposition in rural and urban areas. Science of the Total Environment, 2003, 308, pp.247 - 256. 10.1016/S0048-9697(02)00678-2 . hal-01086752

\section{HAL Id: hal-01086752 \\ https://hal-enpc.archives-ouvertes.fr/hal-01086752}

Submitted on 24 Nov 2014

HAL is a multi-disciplinary open access archive for the deposit and dissemination of scientific research documents, whether they are published or not. The documents may come from teaching and research institutions in France or abroad, or from public or private research centers.
L'archive ouverte pluridisciplinaire HAL, est destinée au dépôt et à la diffusion de documents scientifiques de niveau recherche, publiés ou non, émanant des établissements d'enseignement et de recherche français ou étrangers, des laboratoires publics ou privés.

\section{(c)(1)}

Distributed under a Creative Commons Attribution| 4.0 International License 


\title{
Trace metal determination in total atmospheric deposition in rural and urban areas
}

\author{
Sam Azimi ${ }^{\mathrm{a}, *}$, Alexandre Ludwig ${ }^{\mathrm{b}}$, Daniel R. Thévenot ${ }^{\mathrm{a}}$, Jean-Louis Colin ${ }^{\mathrm{b}}$ \\ ${ }^{a}$ Centre d'Enseignement et de Recherche sur l'Eau, la Ville et l'Environnement (CEREVE), UMR MENRT-MAP 99022 101, \\ Université Paris XII-Val de Marne, Faculté de Sciences et Technologie, 61 Avenue du Général de Gaulle, 94010 Créteil Cedex, \\ France \\ ' Laboratoire Inter Universitaire des Systèmes Atmosphériques (LISA), UMR CNRS 7583, Université Paris XII-Val de Marne, \\ Faculté de Sciences et Technologie, 61 Avenue du Général de Gaulle, 94010 Créteil Cedex, France
}

Received 21 June 2002; accepted 27 November 2002

\begin{abstract}
The wet, dry and total atmospheric depositions of some metals ( $\mathrm{Al}, \mathrm{Cd}, \mathrm{Cr}, \mathrm{Cu}, \mathrm{Fe}, \mathrm{Na}, \mathrm{Pb}$ and $\mathrm{Zn}$ ) were sampled at two sites and atmospheric fallout fluxes were determined for these locations. This work, led by two different research groups, allowed to reach two main goals: to define a simple analytical procedure to secure accurate shipboard sampling and analysis of atmospheric deposition, and to assess anthropogenic impacts of heavy metals to the environment. The first step about the validation step showed that the prevalent deposition type was dry deposition which represents 40,60 and $80 \%$ for $\mathrm{Cd}, \mathrm{Cu}$ and $\mathrm{Pb}$, respectively. This prevalence of dry deposition in total atmospheric fallout supported the necessity of funnel wall rinsing which contains 30,50 and $40 \%$ of collected $\mathrm{Cd}$, $\mathrm{Cu}$ and $\mathrm{Pb}$, respectively. Moreover, the reproducibility of atmospheric deposition collection was determined. The second step was performed by comparing two sampling sites. A rural sampling site, situated in Morvan's regional park (250 km south-east of Paris), was chosen for its isolation from any local and regional contamination sources. Fluxes obtained in this area were compared with those obtained at an urban site (Créteil, suburb of Paris) allowing comparison between urban and rural areas and demonstrating the impact of anthropogenic activities on atmospheric deposition of $\mathrm{Cr}, \mathrm{Cu}$ and $\mathrm{Pb}$.
\end{abstract}

(c) 2002 Elsevier Science B.V. All rights reserved.

Keywords: Trace elements; Atmospheric fallout; Sampling procedures; Anthropogenic impacts

\section{Introduction}

Metal transfer through the atmosphere is a significant part of the biogeochemical cycle of these elements (Galloway et al., 1982). There are two processes which increase heavy metal concentra-

*Corresponding author. Tel.: +33-1-45-17-16-20; fax: + 33-1-45-17-16-27.

E-mail address: azimi@univ-paris12.fr (S. Azimi). tions in the atmosphere: natural and anthropogenic (D'Almeida et al., 1991). Natural sources are mainly composed of soil, sea water and volcanic dusts and gases. Anthropogenic emissions come from industrial gases and aerosols or fossil-fuel combustion (Pacyna, 1984). Incineration of urban waste water treatment sludge and of urban waste were identified as major atmospheric sources of 
trace metals (Sweet and Vermette, 1993; Sullivan and Woods, 2000). Metallic pollutants may be transported over long distances by very small particles (Koutrakis, 1984). These particles when aggregated or washed out by rain are called atmospheric deposition, respectively, dry and wet. Dry deposition of particles occurs by direct impact and gravitational settling on land or water surfaces. In wet deposition, aerosols and gases are dissolved or suspended in water droplets or ice crystals. Besides such long-range transport processes, significant dry and wet depositions also occur locally, and atmospheric sources in urban area may play an important role in the metal contamination of dry and wet depositions (Person et al., 1993). Since heavy metals present high toxicity and high lability in atmospheric fallout (Golomb et al., 1997), their monitoring is important both in urban and rural areas.

The main objective of this work was to validate a weekly collection procedure, both in urban and rural sites, focussing mostly on the determination of total atmospheric deposition. Therefore, during 8 weeks, atmospheric fallout was collected weekly in a rural area in order to set up a sampling and analysis procedure for low concentration of heavy metals. Indeed, a literature survey (Church et al., 1984; Landing et al., 1998; Garnaud, 1999; Thoni et al., 1999) showed that the collection procedures used by different laboratories or institutions present significant differences. Besides the material, size and location of the collector itself, its management, i.e. the collection period, its replacement at the end of each period or the rinsing of aerosol particles adsorbed on the funnel wall are quite different.

The study was completed by an urban collection period of 16 weeks allowing a comparison between urban and rural atmospheric depositions as well as a determination of temporal trends at the urban site.

This work was performed within two research groups, the 'Centre d'Enseignement et de Recherche sur l'Eau, la Ville et l'Environnement' (CEREVE) and the 'Laboratoire Inter Universitaire des Systèmes Atmosphériques' (LISA), both situated within the Créteil University Campus.

\section{Material and methods}

\subsection{Sampling sites}

Two sampling sites were selected to assess the spatial heterogeneity of atmospheric depositions. During a first campaign, from November 1999 to April 2000, four collectors were placed on the roof of University Paris XII-Val de Marne (5 km southeast of Paris, Créteil, France, $20 \mathrm{~m}$ above ground level), within an urban area, at $200 \mathrm{~m}$ from a highway (A86) and $6 \mathrm{~km}$ from an urban waste incineration plant. During a second campaign, from May to July 2000, four other collectors were placed at Saint-Brisson (Morvan's natural park, $250 \mathrm{~km}$ south-east of Paris, France) within a rural area surrounded by forest and lakes, at $2 \mathrm{~km}$ from the closest village and $30 \mathrm{~km}$ from the closest town. A weekly sampling period was chosen for an accurate determination of sampling volume and of heavy metal concentration (Colin, 1997).

\subsection{Total deposition collection}

A simple system made with a high-density polyethylene (HDPE) bottle (1 1) connected to a HDPE funnel was used for total deposition (TD) collection. The funnel cross-sectional areas were $1135 \mathrm{~cm}^{2}$ for CEREVE's and $1810 \mathrm{~cm}^{2}$ for LISA's. All this equipment was placed inside a PVC pipe with PVC needles on top to prevent bird nesting (Fig. 1a). Collector heights varied with site. At Créteil, the collecting funnel was placed at $1.5 \mathrm{~m}$ above the gravel covered university roof (20 m above the ground) and LISA's at $2 \mathrm{~m}$ above the same roof. At Saint Brisson, collection heights were 1.3 and $2 \mathrm{~m}$, respectively, above the grass-covered ground. Comparison between the CEREVE and LISA collectors enabled the assessment of the influence of collection heights on atmospheric deposition measurement. Moreover, the CEREVE TD collector was placed at the same height as the separate dry and wet deposition (DD and WD) collectors (ARS 1000) in order to allow an accurate comparison of TD and the sum DD + WD. Collection bottles were filled in advance with $20 \mathrm{ml}$ of $10 \%$ nitric acid (Nitric acid 65\% Suprapur, Merck) in order to dissolve particulate matter 
(a)

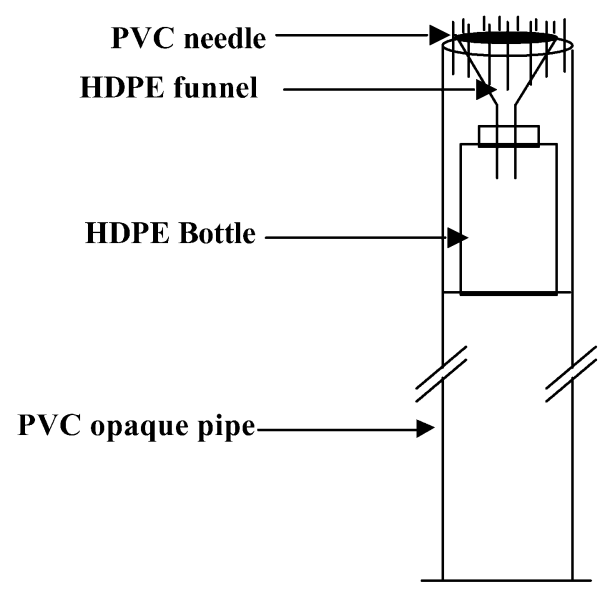

(b)

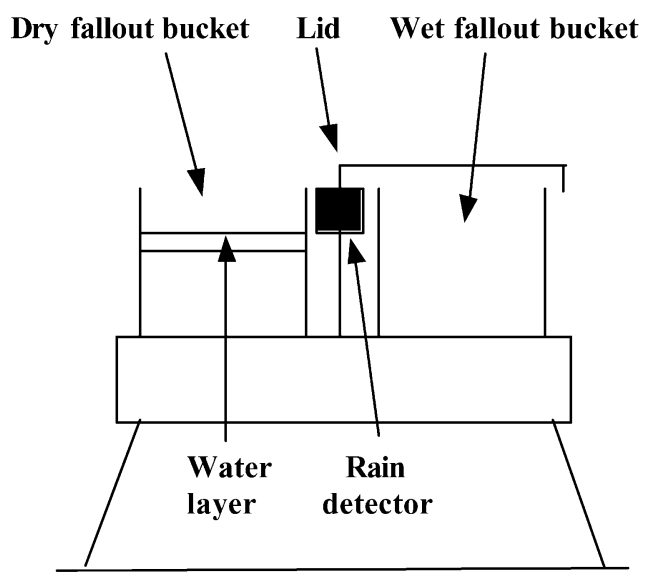

Fig. 1. Atmospheric fallout collectors: (a) total atmospheric deposition collector and (b) separate wet and dry atmospheric deposition collector (ARS 1000, MTX Italia, Modane, Italy).

and to avoid trace metal adsorption on bottle walls. When the rain volume was high, nitric acid was added, within the laboratory clean room, to obtain a final $\mathrm{pH}$ of 1 . At the end of each collection period (7 days), the funnel was rinsed with 100 $\mathrm{ml}$ of a $10 \%$ nitric acid solution (Nitric acid 65\% Suprapur, Merck) and the resulting solution was collected into a separate clean HDPE bottle.

\subsection{Wet and dry depositions collection}

Sampling of TD was supplemented with separate collection of dry and wet atmospheric depositions at each site, using an ARS 1000 equipment (MTX Italia SPA, Modane, Italy). Both types of samples were collected in polyethylene cylindrical vessels (29 $\mathrm{cm}$ inner diameter) covered with a single lid which automatically moves from one container to the other, according to a rain probe (Fig. 1b). Wet deposition was collected in a 17-1 vessel and transferred into smaller bottles (1 11$)$ for easier transport to the laboratory. The vessel used for dry deposition was partially filled with purity water (18.2 $\mathrm{M} \Omega$ Milli-Q water, Millipore S.A.) to a depth of $1 \mathrm{~cm}$ in order to avoid resuspension of collected particles. The evaporation of this water was compensated by an automatic pump triggered by an optical fibre sensor for water level. As it was done for TD collection funnel, DD and WD vessels were rinsed with $100 \mathrm{ml}$ of a $10 \%$ nitric acid solution and the resulting solution was collected in separate clean HDPE bottle.

At the end of each collection period, all collection materials, i.e. for TD, DD and WD, were replaced by clean ones.

\subsection{Collector and vessel cleaning}

For each laboratory this procedure was applied to all materials in contact with wet, dry or total atmospheric fallout samples, i.e. bottles, funnels, ARS vessels, caps and filtration units. The CEREVE procedure was: (1) washing with a sponge and dishwasher detergent, outside of the clean room, and rinsing with deionised water (Milli-Ro, Millipore S.A.); (2) introducing into the clean room and complete immersion into a $2 \%$ Extran bath during $24 \mathrm{~h}$; (3) rinsing with ultra pure water and complete immersion in a $10 \%$ nitric acid bath (Nitric Acid 68\% Normapur, Prolabo) during 24 h.

The LISA procedure was: (1) washing with dishwasher detergent outside the clean room; (2) complete immersion during $24 \mathrm{~h}$ in a $2 \% \mathrm{HCl}$ bath ( $\mathrm{HCl} 36 \%$ Normapur, Merck), then rinsing the material with deionised water before introducing 
into the clean room (class 1000); (3) rinsing with ultra pure water in the clean room and complete immersion into a $2 \% \mathrm{HCl}$ bath for at least 4 days.

The final step was similar in both laboratories: rinsing with ultra pure water and drying before sealing into double plastic bags. All procedures in the clean rooms were performed under class 10 or 100 laminar hoods.

Membranes used for sample filtration (Sartorius, cellulose nitrate, $0.45 \mu \mathrm{m}$ porosity) were treated in the clean room before any use: (1) immersion into a 5\% nitric acid solution during $24 \mathrm{~h}$; (2) rinsing with ultra pure water and storing in a ultra pure water bath.

\subsection{Trace metal analysis}

After samples were brought back to the laboratory and nitric acid was added (when necessary), samples were kept in a dark room at $5{ }^{\circ} \mathrm{C}$ during 7 days in order to dissolve most of particles. Then, samples were filtered under a class 100 laminar hood with $0.45 \mu \mathrm{m}$ porosity filters. The $60-\mathrm{ml}$ sub-samples obtained were kept at $5{ }^{\circ} \mathrm{C}$ until their analysis. The analytical technique used by CEREVE was a Graphic Furnace Atomic Absorption Spectrometer (GF-AAS Perkin-Elmer 1100 B) with Argon flow (Linde, N56) and deuterium lamp for non-specific absorption correction (matrix effect). For cadmium determination, ammonium di-hydrogeno-phosphate $\quad\left(\mathrm{NH}_{4} \mathrm{H}_{2} \mathrm{PO}_{4} \quad\right.$ Merck, Suprapur) was added for matrix modification and prevention of cadmium loss by volatilisation. The analytical technique used by LISA was an ICPAES (Perkin-Elmer Optima 3000) equipped with an ultrasonic nebulisor.

\section{Results and discussion}

\subsection{Validation procedures}

\subsubsection{Prevalent deposition mechanism}

Atmospheric deposition of aerosols and gases occurs in two modes: wet and dry. To obtain total atmospheric loading, it is necessary to measure both wet and dry deposition (Golomb et al., 1997). The measurement of wet deposition is relatively straightforward; it involves the analysis of trace quantities of pollutants, often in concentrations of $\mu \mathrm{g} \cdot 1^{-1}$, in aqueous solution. The measurement of dry deposition is more problematic. In direct measurement of dry deposition, an artificial surface is usually used that simulates the natural surface onto which dry deposition is occurring. In this work, for direct measurements of such depositions, a layer of ultra pure water in a bucket served as a surrogate water surface. A similar method of dry deposition onto a surrogate water surface was used by Golomb et al. (1997) and Morselli et al. (1999). Such a device clearly avoids possible resuspension of aerosols, which have reached this water surface. Nevertheless, in industrial or urban areas, DD was often sampled by immobilising aerosols deposited on an horizontal surface covered with an adhesive polymer named 'DIEM small plate' (NF X 43007-1973). Such adhesion is not complete and aerosols or their metal components may be washed out by rain and wind. Evaluation of this loss was done by the comparison of the DD collector and the rinsing step of the funnel walls which simulated a dry nature surface.

In countries with temperate climate and limited precipitation, it is important to evaluate the relative importance of DD through aerosol settling and of WD through rain. Indeed, during wet weekly periods, with average daily rainfall amounts above $10 \mathrm{~mm} \cdot$ day $^{-1}, \mathrm{Cd}, \mathrm{Cu}$ and especially $\mathrm{Pb}$ are mainly deposited as DD (Fig. 2): the mean relative importance of DD at the rural site reaches 40, 60 and $80 \%$ for $\mathrm{Cd}, \mathrm{Cu}$ and $\mathrm{Pb}$, respectively. This prevalence of $\mathrm{DD}$ has also been observed at Créteil: the relative importance of DD reached 67, 73 and $76 \%$ for $\mathrm{Cd}, \mathrm{Cu}$ and $\mathrm{Pb}$, respectively. In central Paris (Garnaud, 1999), DD represented 77, 83 and $87 \%$ of TD for $\mathrm{Cd}, \mathrm{Cu}$ and $\mathrm{Pb}$, respectively. These results show the importance of DD relative to WD in both areas.

\subsubsection{Rinsing step}

The device used most frequently for collecting TD consists of a funnel connected to a receiving bottle (Fig. 1a). When aerosols settle on the funnel wall, they easily adhere, adsorb and accumulate on its walls and are mostly transferred to the bottle during a rain event. An unknown and poorly controlled part of such aerosols accumulated on 


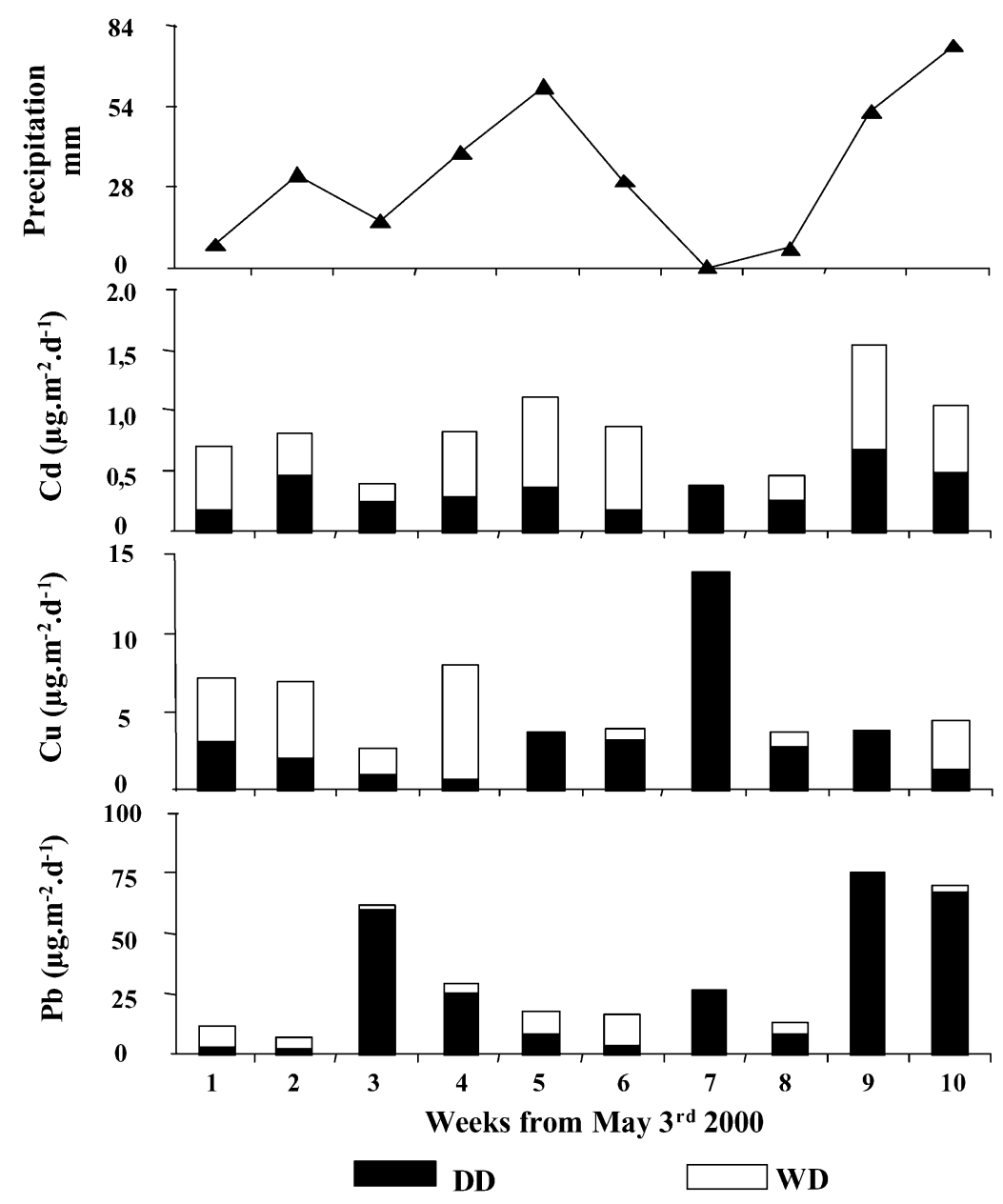

Fig. 2. Week average of Morvan's daily flow of dry (DD) and wet (WD) atmospheric depositions $\left(\mu \mathrm{g} \cdot \mathrm{m}^{-2} \cdot \mathrm{d}^{-1}\right) \mathrm{for} \mathrm{Cd}, \mathrm{Cu}$ and $\mathrm{Pb}$ as well as rainfall amounts $(\mathrm{mm})$ during each sampling period.

funnel walls may be resuspended during windy periods: this is not the case of aerosol trapped by the water layer of the DD collector. Thus, the sum of DD and WD metal fluxes, as determined by ARS 1000 equipment, is larger than the TD metal flux, during the same period: at the rural site, cumulated fluxes of DD + WD are 4 and 1.5 times higher than $\mathrm{TD}$, for $\mathrm{Pb}$ and $\mathrm{Cd}$, respectively. In the urban area, the same comparison for $\mathrm{Cd}, \mathrm{Cu}$ and $\mathrm{Pb}$ collected by ARS 1000 and TD collector shows no difference, i.e. (DD + WD)/TD ratio calculated for cumulated fluxes are 1.07, 1.11 and 0.94 for $\mathrm{Cd}, \mathrm{Cu}$ and $\mathrm{Pb}$, respectively. This differ- ence between urban and rural areas is probably caused by the highest amount of metals adsorbed on the TD funnel walls in urban area. Indeed, a thin black soot layer was deposited on the funnel walls at Créteil site. This latter, playing a role similar to the water layer in the DD collector, may prevent particles deposited on funnel walls to be resuspended by wind. We have attempted to demonstrate this adsorption mechanism by rinsing the funnel at the end of each collection period and by determining heavy metals in the sample obtained during such an acid rinsing step. Fig. 3 demonstrates that during the whole campaign performed 


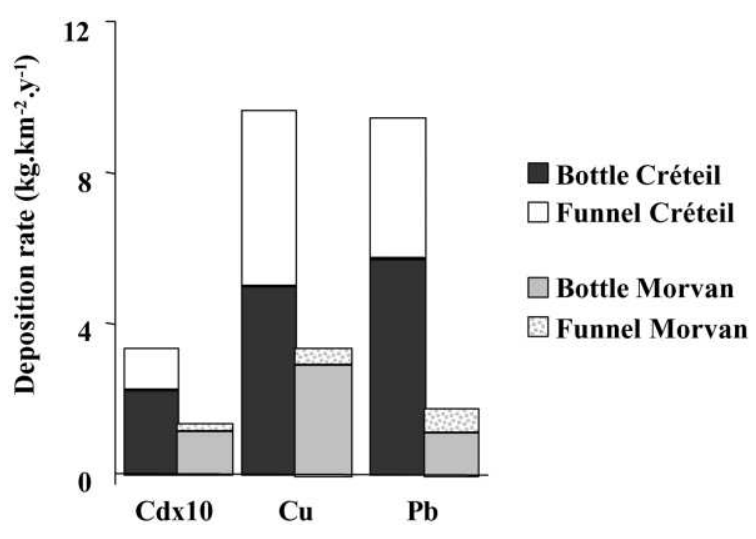

Fig. 3. Comparison of $\mathrm{Cd}, \mathrm{Cu}$ and $\mathrm{Pb}$ total deposition rate $(\mathrm{kg}$ $\mathrm{m}^{-2}$ year $^{-1}$ ) integrated over both campaigns performed at Créteil and Morvan sites (1999-2000): each deposition rate is the sum of the contribution of samples present in collecting bottles (bottom part) and obtained during acid rinsing of collecting funnels (top part).

at Créteil, the atmospheric metal fluxes calculated from samples obtained by acid rinsing of the funnel are significant, reaching a relative importance of 30,50 and $40 \%$ for $\mathrm{Cd}, \mathrm{Cu}$ and $\mathrm{Pb}$, respectively. In the rural area, the relative importance of the rinsing step is lower and reaches 14, 13 and $30 \%$ for $\mathrm{Cd}, \mathrm{Cu}$ and $\mathrm{Pb}$, respectively. The lower importance of the rinsing step in a rural area, i.e. without an adhesive system (water or soot), demonstrates the possible resuspension of aerosols by wind. However, the acid rinsing procedure of funnels is probably far from being complete: this is especially clear in urban areas where black soot deposits have been often observed (Garnaud, 1999). Such black deposits are not totally released by acid rinsing and even after long immersion in detergent bath, it is often necessary to wipe them out with tissues. Although some procedures used by regional or international networks, monitoring total atmospheric deposits, neglect the amount of metals deposited on the funnels, we are convinced that at the end of each sampling period, such funnels should be acid rinsed and replaced by clean ones.

\subsubsection{Collection procedure reproducibility}

A comparison was performed between our two research groups at both the Créteil and Morvan sites. Each laboratory used its own clean room, reagents, material and analytical technique. The statistical one-tailed $t$-test was used to compare the mean flux values obtained by each laboratory at each site. Results obtained both in rural and urban areas showed no significant difference between the two research groups for the $99 \%$ CI. Furthermore, if we exclude $\mathrm{Zn}$ flux in the rural site, we could observe a good agreement between values measured at each site with published data collected in similar land occupation sites (Tripathi et al., 1993; Vukmirovic et al., 1997; Hovmand and Kemp, 1998; Garnaud, 1999; Ridame et al., 1999). Indeed, our results are in the same order of magnitude than previous studies.

\subsubsection{Validation of trace metal analysis}

The validation procedure presents three steps using laboratory blanks (LB), field blanks (FB) and samples certified for trace metals.

LBs were chosen as the rinsing solutions (10\% nitric acid) which were used for the rinsing step: the metal analysis was performed after the filtration of the solution through a $0.45 \mu \mathrm{m}$ pore filter in our clean room. This procedure allows the assessment of possible contamination by sample handling within the clean room. The detection limit (DL) of both GF-AAS and ICP-AES (Desboeufs et al., 1999) have been calculated as three times the standard deviation of 10 laboratory blanks analysis.

FBs were prepared to assess the material contamination during transport and installation on sites. Total deposition FB was prepared using 20 $\mathrm{ml}$ of $10 \%$ nitric acid which had been transported to the sampling site, placed on the standing PVC pipe and brought back to the laboratory. Dry deposition FB was prepared as the water layer contained in the collecting vessel, transported back to the laboratory just after filling it on the site. Wet deposition FB was prepared using the rinsing solution, which was poured into a clean sampling bucket at the sampling site, and brought back to the laboratory. Table 1 compares DL, LB and FB for each analytical technique (GF-AAS and ICPAES), as well as 10th and 90th percentiles $\left(d_{10}\right.$ and $d_{90}$ ) of metal concentrations determined at the Morvan site. Tenth percentile was taken for com- 
Table 1

Comparison of detection limits (DL), laboratory and field blank mean and standard deviation results obtained using GF-AAS and ICP-AES, and 10th $\left(d_{10}\right)$ and 90th $\left(d_{90}\right)$ percentiles of metal concentrations in TD samples collected at Morvan site $\left(\mu \mathrm{g} \cdot 1^{-1}\right)$

\begin{tabular}{|c|c|c|c|c|c|c|c|c|}
\hline & \multicolumn{3}{|c|}{ GF-AAS } & \multicolumn{3}{|c|}{ ICP-AES } & \multicolumn{2}{|c|}{ TD at Morvan } \\
\hline & DL & $\begin{array}{l}\text { Lab blank } \\
(m \pm \sigma) \\
(n=10)\end{array}$ & $\begin{array}{l}\text { Field blank } \\
(n=1)\end{array}$ & DL & $\begin{array}{l}\text { Lab blank } \\
(m \pm \sigma) \\
(n=4)\end{array}$ & $\begin{array}{l}\text { Field blank } \\
(m \pm \sigma) \\
(n=4)\end{array}$ & $d_{10}$ & $d_{90}$ \\
\hline $\mathrm{Al}$ & & & & 0.3 & $4.4 \pm 2.8$ & $3.2 \pm 1.9$ & 20 & 280 \\
\hline $\mathrm{Cd}$ & 0.03 & $0.01 \pm 0.01$ & 0.04 & 0.05 & $0.23 \pm 0.03$ & $0.19 \pm 0.09$ & 0.17 & 0.58 \\
\hline $\mathrm{Cr}$ & & & & 0.07 & $0.56 \pm 0.10$ & $0.41 \pm 0.23$ & 0.45 & 1.0 \\
\hline $\mathrm{Cu}$ & 0.09 & $0.01 \pm 0.03$ & 0.09 & 0.06 & $0.36 \pm 0.04$ & $0.41 \pm 0.15$ & 3.2 & 14.0 \\
\hline $\mathrm{Fe}$ & & & & 0.05 & $0.65 \pm 1.20$ & $2.81 \pm 1.33$ & 27 & 250 \\
\hline $\mathrm{Na}$ & & & & 0.5 & $1.12 \pm 0.70$ & $3.22 \pm 1.58$ & 34 & 230 \\
\hline $\mathrm{Pb}$ & 0.30 & $0.17 \pm 0.10$ & $<\mathrm{DL}$ & 0.6 & $0.51 \pm 0.19$ & $0.62 \pm 0.04$ & 2.9 & 90.1 \\
\hline $\mathrm{Zn}$ & & & & 0.03 & $1.72 \pm 3.39$ & $2.26 \pm 1.29$ & 10 & 32 \\
\hline
\end{tabular}

parison with DL and blanks in order to estimate the validity of each analytical method. DL obtained by both analytical techniques are below the $d_{10}$ value for all heavy metals. The comparison between $\mathrm{LB}$ and $d_{10}$ shows that the material cleaning and sampling treatment procedure have no significant effect on heavy metals analysis except for $\mathrm{Cr}$ and $\mathrm{Cd}$. For $\mathrm{Cr}$, the LB levels are equivalent or higher than $d_{10}$ and for Cd, the LB is higher than $d_{10}$ only with ICP-AES. Moreover, comparison between $\mathrm{FB}$ and $d_{10}$ showed that except for $\mathrm{Cr}$ and $\mathrm{Cd}$, FB values obtained by ICPAES are less than $20 \%$ of $d_{10}$. In the case of $\mathrm{Cd}$, only the GF-AAS method gave FB values that were up to $20 \%$ of sample $d_{10}$. As a consequence, procedures have to be improved for decreasing $\mathrm{Cr}$ contamination in sample handling as well as $\mathrm{Cd}$ analyse by ICP-AES. The latter conclusion illustrates that GF-AAS is a more sensitive technique for $\mathrm{Cd}$ determination in atmospheric fallout.

The accuracy of the analytical results was verified using three samples certified in trace metals: (1) NIST 1643d 'Trace elements in water', US Department of Commerce, National Institute of Standards and Technology, Gaithersburg, MD 20 899, USA; (2) SPS-SW1 'Surface Water (batch 105)', Spectra-Pure Standards, Promochem, Molshelm, France; and (3) SLRS 'Saint-Laurent River Surface', Geological Survey Quality Assurance Branch, Canada. These certified samples were chosen because they had heavy metal concentrations similar to those found in atmospheric depo- sition (Table 2). These certified samples were introduced into each set of analysed samples. For some elements $(\mathrm{Cd}, \mathrm{Cu}, \mathrm{Fe}$ and $\mathrm{Na})$, deviation between measured and certified values are less than $10 \%$. In the $\mathrm{Pb}$ case, there is a relatively high deviation between certified and measured values (54\%) for low concentrated samples, but this level is 10 times lower than $90 \%$ of measured values in the rural area. For other elements ( $\mathrm{Al}, \mathrm{Cr}$ and $\mathrm{Zn}$ ), the deviation is between 15 and $25 \%$, but measured concentrations are included in the uncertainty interval given for the certified values. Therefore, analytical conditions are considered as validated for atmospheric trace metal analysis.

\subsubsection{Flux assessment}

The uncertainty of concentration measurement varies from method to method (i.e. ICP-AES and GF-AAS), and also from species to species. Generally, the concentration measurements of standard samples were within $10-20 \%$ of the nominal values. However, in atmospheric deposition measurement the major source of uncertainty is not the concentration measurement, but in the method of collecting deposition samples (Golomb et al., 1997). For wet deposition, there may be some loss of the fine rain drops (or light snow flakes), especially under wind conditions. For dry deposition measurement, both the water layer method and the funnel method have major uncertainties that are difficult to quantify. Bucket and funnel walls present a significant aerodynamic interfer- 
ence to particle (and gaseous molecule) deposition. Particles, especially in the sub-micron to micron size range, are subject to Brownian, wind and turbulent eddy motion, and may be blown over and around the bucket or funnel walls rather than deposited into it. Once inside the funnel or bucket, the particles may adhere to the walls or deposit in the bottom of the collector. While we did rinse the collector walls with acid and analysed the rinse solution for metals, the deposition area was taken only as the top area of the collector.

\subsection{Heavy metal impact}

\subsubsection{Comparison between urban and rural dep- osition fluxes}

Total atmospheric deposition fluxes were compared using fluxes integrated over the whole campaigns conducted at our urban and rural sites (Fig. 4). The impact of human activities in Créteil area could be seen on several metals like $\mathrm{Pb}, \mathrm{Cu}, \mathrm{Cd}$, $\mathrm{Na}, \mathrm{Al}, \mathrm{Cr}$ and $\mathrm{Fe}$. This influence was more obvious for $\mathrm{Cu}, \mathrm{Cd}$ and $\mathrm{Pb}$ which have only anthropogenic sources, as opposed to four other metals, which also have many natural sources (Pacyna, 1984; Person et al., 1993; Sullivan and Woods, 2000). Total atmospheric Zn fluxes were surprisingly high at our rural site of the Morvan regional park. The high concentration of this element was probably induced by work done during our sampling period on building roof, which is made with $\mathrm{Zn}$-covered metal sheets located $100 \mathrm{~m}$

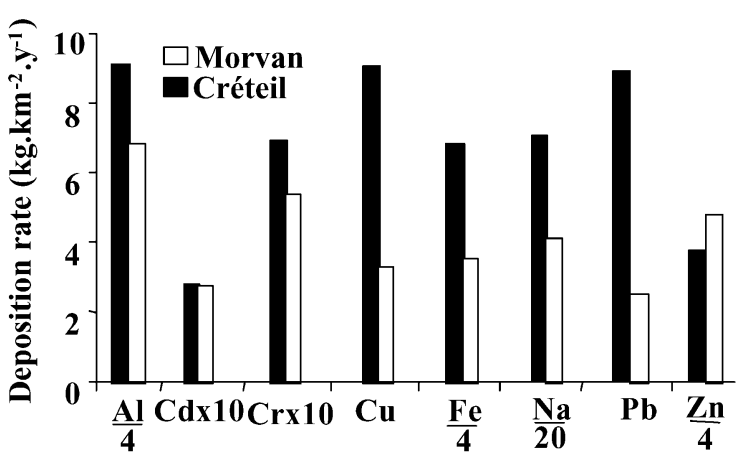

Fig. 4. Comparison of urban (Créteil) and rural (Morvan) total atmospheric deposition rate $\left(\mathrm{kg} \cdot \mathrm{km}^{-2} \cdot \mathrm{year}^{-1}\right)$ integrated over both 1999-2000 campaigns.

from our collectors. Indeed, we have noticed that our TD determination for $\mathrm{Zn}$ in Morvan park is higher than previous works done in rural areas (Migon et al., 1997; Ridame et al., 1999) and lower than other results in urban areas (Tripathi et al., 1993; Vukmirovic et al., 1997). Such differences may be related to the presence of point sources, which are clearly site-specific.

\subsubsection{Evolution of trace metal deposition fluxes}

Determination of DD and WD fluxes was performed at the same Créteil site in 1994 using the same collecting equipment ARS 1000 (Garnaud, 1999). Fig. 5 shows the 5-year trend of $\mathrm{Pb}, \mathrm{Cu}$ and Cd TD fluxes assessed by the sum of DD and WD: a decrease appears for all three heavy metals.

Table 2

Samples certified concentration used in this work as well as 10th $\left(d_{10}\right)$ and 90th $\left(d_{90}\right)$ percentiles concentration values of metal in TD samples collected at Morvan site $\left(\mu g \cdot 1^{-1}\right)$

\begin{tabular}{|c|c|c|c|c|c|c|c|c|c|c|c|}
\hline & \multicolumn{3}{|c|}{ SRM 1643d } & \multicolumn{3}{|c|}{ SPS SW1 } & \multicolumn{3}{|l|}{ SLRS } & \multicolumn{2}{|c|}{ TD at Morvan } \\
\hline & C.V. & M.V. & $D$ & C.V. & M.V. & $D$ & C.V. & M.V. & $D$ & $d_{10}$ & $d_{90}$ \\
\hline $\mathrm{Al}$ & 127 & 156.58 & $23 \%$ & 50 & 51.09 & $2 \%$ & 90.64 & 93.2 & $3 \%$ & 20 & 280 \\
\hline $\mathrm{Cd}$ & 6.47 & 6.32 & $-2 \%$ & 0.5 & 0.46 & $-8 \%$ & 0.028 & 0.03 & $7 \%$ & 0.17 & 0.58 \\
\hline $\mathrm{Cr}$ & 18.5 & 18.96 & $2 \%$ & 2 & 2.29 & $15 \%$ & 0.48 & 0.5 & $4 \%$ & 0.45 & 1.0 \\
\hline $\mathrm{Cu}$ & 20.5 & 22.2 & $8 \%$ & 20 & 20.2 & $1 \%$ & 2.76 & 2.9 & $5 \%$ & 3.2 & 14.0 \\
\hline $\mathrm{Fe}$ & 91 & 92.57 & $2 \%$ & 20 & 20.94 & $5 \%$ & 128 & 134 & $5 \%$ & 27 & 250 \\
\hline $\mathrm{Na}$ & 22.1 & - & - & 2000 & 1890 & $-5 \%$ & 1862 & 1925 & $3 \%$ & 34 & 230 \\
\hline $\mathrm{Pb}$ & 18.15 & 17.7 & $-2 \%$ & 5 & 4.96 & $-1 \%$ & 0.13 & 0.2 & $54 \%$ & 2.9 & 90.1 \\
\hline $\mathrm{Zn}$ & 72.5 & 57.75 & $-20 \%$ & 20 & 14.99 & $-25 \%$ & 3.33 & 3.6 & $8 \%$ & 10 & 32 \\
\hline
\end{tabular}

C.V. are the certified values; M.V. are the measured values which were obtained by the median of 10 analysed samples; $D$ is the deviation between certified and measured values. Values in bold were obtained by GF-AAS. 


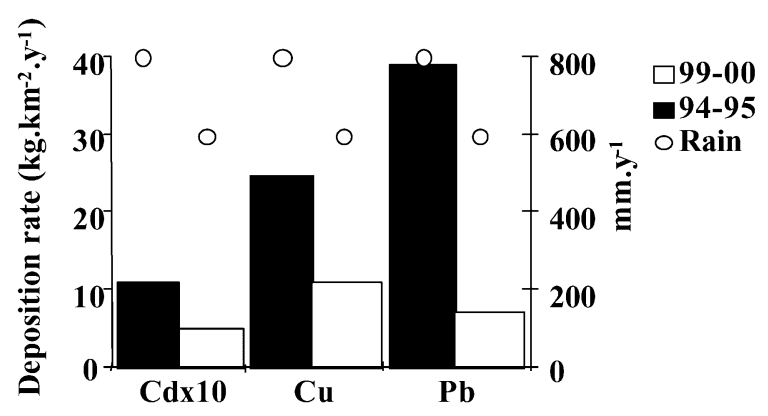

Fig. 5. Comparison between total atmospheric annual deposition rate $\left(\mathrm{kg} \cdot \mathrm{km}^{-2} \cdot\right.$ year $\left.^{-1}\right)$ integrated during 5 month campaigns performed at Créteil in 1994-1995 and 1999-2000 winter periods, using the sum of monitored DD and WD fluxes, and mean rainfall amount $\left(\mathrm{mm} \cdot\right.$ year $\left.^{-1}\right)$ during both sampling periods.

Indeed, $\mathrm{Pb}, \mathrm{Cu}$ and $\mathrm{Cd}$ fluxes drop by a factor of 5, 2 and 2, respectively. During both sampling periods registered rainfall amount was not very different, i.e. 800 and $600 \mathrm{~mm} \cdot$ year $^{-1}$ in 1994 and 1999, respectively: such a weak difference could not explain such a high TD decrease. Better treatment of smoke emissions by various waste or sludge incinerators or power plants is more likely to be responsible for such large improvements in air quality.

\section{Conclusions}

During 8 weeks, atmospheric fallouts were collected weekly in a rural area in order to set up a sampling and analysis procedure for low concentrated heavy metal samples. The study was completed by a 16-week urban collection period, thus allowing a comparison between urban and rural atmospheric depositions as well as a determination of temporal trends at Créteil.

A simple method of total atmospheric deposition collection using a HDPE funnel and bottle standing at $1.5 \mathrm{~m}$ above the ground within a PVC pipe was assessed. Twenty millilitres of nitric acid was placed into the bottle before the sampling period in order to dissolve all the collected particles. Nevertheless, the funnel acid rinsing appeared to be an important step of the collection procedure. This step is clearly related to the importance of
DD within TD, as evidenced both in rural and urban sites. The analytical techniques used (GFAAS and ICP-OES) in this work allowed the determination of low concentration levels of some heavy metals like $\mathrm{Al}, \mathrm{Fe}, \mathrm{Na}, \mathrm{Pb}, \mathrm{Cu}$ and $\mathrm{Zn}$. But for some other metals ( $\mathrm{Cd}$ and $\mathrm{Cr}$ ), an improvement has to be achieved in material cleaning and collection procedures to ensure the quality of their determination. Comparison of trace metal deposition fluxes determined separately at CEREVE and LISA, showed good agreement: this resulted in well-defined collection and analytical procedures, including thorough vessel cleaning and the use of clean rooms.

An illustration of the impact of human activities on urban atmospheric fallout was evidenced by comparing Morvan and Créteil heavy metal TD: the most important differences in $\mathrm{Pb}$ and $\mathrm{Cd}$ were related to their emission by anthropogenic sources. Such urban impact was found to decrease very significantly between 1994 and 1999 for $\mathrm{Pb}, \mathrm{Cu}$ and $\mathrm{Cd}$ TD fluxes, demonstrating the recent improvement in the treatment of smoke produced by anthropogenic activities.

\section{Acknowledgments}

This work was supported by the atmospheric department of ADEME and by the PIREN-Seine research program (CNRS GDR 1067). The authors are grateful to Vincent Rocher (CEREVE) and Myriam Harry (Laboratoire de Biologie des Sols et des Eaux) for their scientific support.

\section{References}

Church TM, Tramontano JM, Scudlark JR, Jickells TD, Tokos JJ, Knap AH, Galloway JN. The wet deposition of trace metals to the western Atlantic Ocean at the mid-Atlantic coast and on Bermuda'. Atmos Environ 1984;18(12):26572664.

Colin JL. Physico-chimie de la phase aqueuse atmosphérique. Eighth Environment Science and Technology International Symposium, Créteil, France 1997. p. 7-15.

D’Almeida GA, Koepke P, Shettle EP. Atmospheric aerosols: global climatology and radiative characteristics. A. Deepak publishing, 1991. (561 pp).

Desboeufs KV, Losno R, Vimeux F, Cholbi S. pH dependent dissolution of wind transported Saharan dust. J Geophys Res 1999;104:21287-21299. 
Galloway JN, Thorton JD, Norton SA, Volchok HL, McLean RAN. Trace metals in atmospheric deposition: a review and assessment. Atmos Environ 1982;16(7):1677-1700.

Garnaud S. Transfert and geochemical evolution of metal pollution in an urban catchment. Environmental Science and Technology PhD. Ecole Nationale des Ponts et Chaussées, 1999. (393 pp).

Golomb D, Ryan D, Eby N, Underhill J, Zemba S. Atmospheric deposition of toxic onto Massachusetts Bay-I. Metals. Atmos Environ 1997;31(9):1349-1359.

Hovmand MF, Kemp K. Heavy metal bulk deposition and aerosol concentrations in rural Denmark 1992-1996. Environmental Research Institute Final Report. Denmark: Roskilde, 1998. (11 pp).

Koutrakis P. Physico-chimie de l'aérosol urbain: identification et quantification des principales sources par analyse multivariable. Atmospheric Environment $\mathrm{Ph} \mathrm{D}$. University Paris XII-Val de Marne, 1984. (143 pp).

Landing WM, Guentzel JL, Gill GA, Pollman CD, Lindberg SE, Petersen G, Keeler G. Methods for measuring mercury in rainfall and aerosols in Florida. Atmos Environ 1998;32(5):909-918.

Migon C, Journel B, Nicolas E. Measurement of trace metal wet, dry and total atmospheric fluxes over the Ligurian Sea. Atmos Environ 1997;31(6):889-896.

Morselli L, Cecchini M, Grandi E, Iannuccilli A, Barrili L, Olivieri P. Heavy metals in atmospheric surrogate dry deposition. Chemosphere 1999;38(4):899-907.
Pacyna JM. Estimation of the atmospheric emissions of trace elements from anthropogenic sources in Europe. Atmos Environ 1984;18(1):41-50.

Person A, Petit-Coviaux F, Le Moullec Y, Festy B. Contribution des principales sources en métaux et métalloïdes à la pollution particulaire dans l'agglomération Parisienne. Pollut Atmos 1993;75-88.

Ridame C, Guieu C, Loÿe-Pilot M-D. Trend in total atmospheric deposition fluxes of aluminium, iron, and trace metals in the northwestern Mediterranean over the past decade (1985-1997). J Geophys Res 1999;104(D232):3012730138.

Sullivan R, Woods I. Using emission factors to characterise heavy metal emissions from sewage sludge incinerators in Australia. Atmos Environ 2000;34:4571 -4577.

Sweet CW, Vermette SJ. Sources of toxic element in urban air in Illinois. Environ Sci Technol 1993;27:2502-2510.

Thoni L, Krieg F, Siewers U. Testing the Bergerhoff method to determine the bulk deposition loads of 49 elements. Atmos Environ 1999;33(2):337-344.

Tripathi RM, Ashawa SC, Khandekar RN. Atmospheric deposition of $\mathrm{Pb}, \mathrm{Cd}, \mathrm{Cu}$ and $\mathrm{Zn}$ in Bombay, India. Atmos Environ 1993;27B(2):269-273.

Vukmirovic Z, Marendic Miljkovic J, Rajsic S, Tasic M, Novakovic LA. Resuspension of trace metals in Belgrade under conditions of drastically reduced emission levels. Water Air Soil Pollut 1997;93(1-4):137-156. 